\title{
Contagion Channels of the Subprime Financial Crisis to the NYSE Euronext European Markets using Copulas ${ }^{1}$
}

Paulo Jorge de Brito Horta*

Sergio Lagoa **

Luis Filipe Martins ***

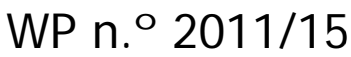

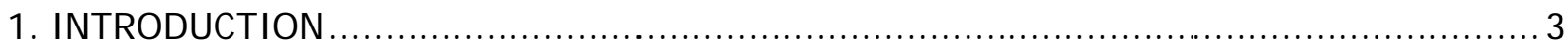

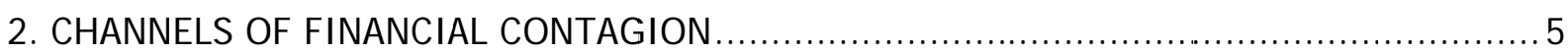

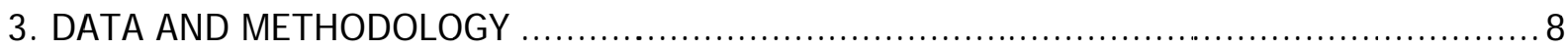

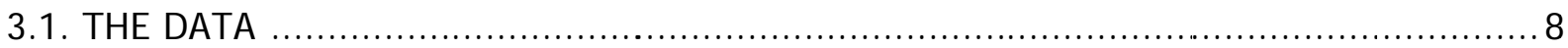

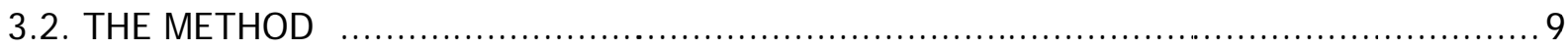

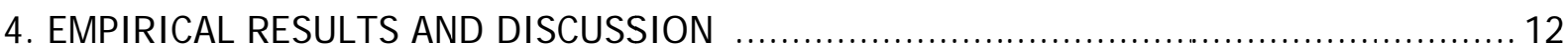

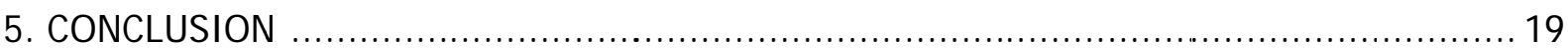

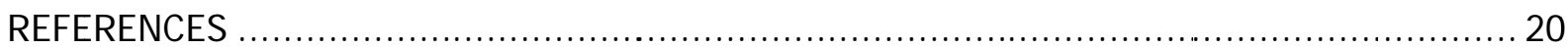

\footnotetext{
${ }^{1}$ We thank Emanuel Leão for his comments. The usual disclaimer applies.

* Portuguese Securities Market Commission, CMVM - Lisbon, Portugal. Av. Liberdade, 252, 1056-801 Lisbon, Portugal; Telephone: 00351213177000. Email: paulohorta@cmvm.pt.

** Instituto Universitário de Lisboa (ISCTE-IUL), DINÂMIA'CET-IUL, Lisboa, Portugal. Email: sergio.lagoa@iscte.pt.

*** Instituto Universitário de Lisboa (ISCTE-IUL), Department of Quantative Methods. Email: luis.martins@iscte.pt.
} 



\title{
Contagion Channels of the Subprime Financial Crisis to the NYSE Euronext European Markets using Copulas
}

\begin{abstract}
This paper tests whether there was contagion of the Subprime financial crisis to the European stock markets of the NYSE Euronext group (Belgium, France, the Netherlands and Portugal) and, if evidence of contagion is found, determines the transmission channel(s) through which the crisis was propagated. We date the beginning of the crisis as $1^{\text {st }}$ August 2007 after the burst of the U.S. subprime bubble, ending on $7^{\text {th }}$ December 2009 with the emergence of the Greek sovereign debt crisis.

After assessing whether there is evidence of financial contagion in the stock markets, we examine whether the "wealth constraints" transmission mechanism prevails over the "portfolio rebalancing" mechanism. An additional test looks at the interaction between stock and bond markets during the crisis and allows us to determine if the transmission occurs due to the "cross market rebalancing" channel or to the "flying to quality" phenomenon.

We use copula theory to model the dependence structure between the U.S. stock market and the other stock markets in the sample, during the pre-crisis and the turmoil period. The tests suggest that i) financial contagion is present in all analysed stock markets, ii) the "portfolio rebalancing" channel is the most important crisis transmission mechanism, iii) and the "flight to quality" phenomenon is also present in all analysed stock markets.
\end{abstract}

Keywords: financial contagion; 2008 financial crisis; stock markets; copula theory.

JEL classification: F30, G14, G15. 



\section{INTRODUCTION}

In a financially globalized world, it seems that financial crises spread quickly from country to country. A good example of such a phenomenon is the propagation of the 1997 Asian financial crisis that affected not only Asian countries, but also distant countries like Brazil, Russia and even developed countries.

The literature describes many ways through which financial crises spread across countries. Crisis contagion has been one of the main topics of study. Even though there are many definitions of financial contagion (Pericoli and Sbracia, 2003), which are adapted to the specific nature of each study, the Forbes and Rigobon (2002) definition of shift contagion is one of the most used. This refers to a "significant increase in cross-market linkages after a shock to an individual country (or group of countries)". From a practical standpoint, there is financial contagion when the correlation between the returns of two markets suffers a statistically significant increase after an unexpected event. This is the definition of contagion adopted in this paper.

According to Kodres and Pritsker (2002), the financial crisis contagion literature has three branches. The first relates exchange rates crises with the imperfections of financial markets and weaknesses of monetary and fiscal policies, thus making the country vulnerable to speculative attacks. The second branch highlights systemic connections between financial institutions as the main cause of crisis transmission. Finally, the third branch focuses on financial markets, namely stock markets, as the main channel of transmission. Our study concerns this last mechanism of transmission.

Studies on the role of financial markets in crisis contagion underline two main channels through which transmission can occur: the fundamental or real channel, connected to international trade and foreign direct investment; and the financial channel, related to investors' behaviour. Boyer, Kumagai and Yuan (2006) argue that there is little evidence that the real channell is the main mean of transmission. But there is not even consensus among those studies that recognize the preponderance of the investors' channel on whether this channel works through portfolios adjustments or through wealth constraints impositions. Our study aims to contribute to this debate by looking at the mechanisms of financial contagion of the Subprime crisis to the financial markets of NYSE Euronext.

The literature acknowledges the existence of contagion in financial markets due to the Subprime crisis. Fry, Martin and Tang (2010) propose a new set of tests based on the change of coskewness of the distribution of returns during the financial crisis and conclude for existence of contagion during the Subprime crisis. Idier (2011) and Guo, Chen and Huang (2011), using Markov switching models, and Gallegati (2010) with Wavelet representations reach a similar conclusion. Moreover, Dungey, Fry, Gonzáles-Hermosillo, Martin and Tang (2008) use a factor model estimated by GMM to show that there was contagion in both emergent and developed markets in the Russian crisis of 1998, in the Long-Term Capital Management crisis of the second half of 1998, in the Brazilian crisis of 1999, in 
the Dot.com crisis of 2000, in the Argentina Crisis of 2001 and in the Subprime crisis of 2007. Contagion was particularly strong in the Russian and Subprime crises.

It is indeed relevant to test for financial contagion but, most importantly, the channels through which it occurs need to be identified. Firstly, financial crisis have large costs, especially in terms of the stability of financial institutions, economic growth and employment. Therefore, understanding how these crises spread is important for policy makers so that they can take adequate measures to prevent or contain the spread of crises, especially by regulating financial institutions and managing expectations. Secondly, the existence of financial contagion has strong implications for international portfolio management. In fact, if stock return correlation across countries increases after a negative shock in a country, then the advantages of international diversification are reduced precisely when they were most needed (Longin and Solnik, 2001; Ang and Chen, 2002; Ang and Bekaert, 2002). Consequently, financial institutions will also be more exposed to risk in the presence of contagion. Thus, it is important to understand stock markets' co-movements in crises so as to improve portfolio management and financial institutions supervision.

As mentioned above, the literature does not always agree on the channels causing the propagation of crises. It naturally depends on the type of crisis in question and the statistical approach adopted. Boyer, Kumagai and Yuan (2006) study the transmission of the 1997 Asian Crisis to developed and emergent markets. They conclude that this crisis was propagated to emergent markets through wealth constraints, and to developed markets through portfolio rebalancing. Empirical studies on the importance of portfolio rebalancing to contagion found weak evidence of macroeconomic factors as the main means of transmitting crises (Boyer, Kumagai and Yuan, 2006). For example, the empirical evidence of Karolyi and Slutz (1996) and Connoly and Wang (2003) concludes that macroeconomic announcements and other public information do not affect the co-movement between the US and Japanese stock markets. King, Sentana and Wadhwani (1994) show that economic variables only explain a small fraction of co-movement between international stock markets. Moreover, Forbes (2002) finds that despite evidence of trade links explaining contagion of crises, their explanatory capacity is only partial. Finally, there is evidence that international mutual fund holdings are a mechanism through which crises propagate (Boyer, Kumagai and Yuan, 2006).

With respect to the Subprime crisis, Chudik and Fratzscher (2012) use a global VAR methodology and show that investors had a flight-to-safety behaviour during that crisis, with financial capital moving from emerging market economies to bond markets of the US and other advanced economies. Also studying the 2007-08 crisis, Longstaff (2010) concluded that financial contagion occurred essentially through liquidity and risk-premium channels. He uses a VAR methodology, divides the sample into three periods (years 2006-2008), and focuses on the collateralized debt obligation market. However, in the present paper we use stock and bond returns in a cross country analysis; we follow the 
contagion channels classification as in Boyer, Kumagai and Yuan (2006); and propose the copula theory as the appropriate statistical tool to pursue our objectives.

There are advantages of using copulas instead of the analysis of correlation coefficients. Besides allowing for non-linear dependences, copulas also measure extreme events. For example, asymptotic tail coefficients measure the probability that stock markets suffer large increases or decreases simultaneously. Moreover, it allows returns to have asymmetric and heavy tail distributions, which some empirical evidence has shown to be adequate to describe financial returns.

Horta, Mendes and Vieira (2010) concluded for a smaller dataset that there was contagion of the US subprime crisis to the European stock markets of the NYSE Euronext group. We now confirm that result and add that the portfolio rebalancing channel is the most important crisis transmission mechanism and that the flight-to-quality phenomenon is present in all analysed stock markets.

The remainder of the paper is organized as follows. Section 2 defines the channels of transmission of financial crises in stock markets. In Section 3 we describe the sample, methodology and the hypotheses of interest. In Section 4 the main results are presented and discussed. Finally, Section 5 concludes.

\section{CHANNELS OF FINANCIAL CONTAGION}

In this section, we describe the main channels of financial contagion and suggest some empirical tests to distinguish between them; we point out the main weaknesses of using the correlation coefficient and explain our use of copulas.

According to Dungey et al. (2004), the first empirical tests of contagion were performed by Sharpe (1964) and Grubel and Fadner (1971). The literature has since grown and a range of methodologies has been used to measure contagion, including probit and logit models, advanced indicators, GARCH models, Markov switching models and correlations between returns (Pericoli and Sbracia, 2003).

The analysis of correlation coefficients has been the most common method to assess comovement between markets during crises. For instance, Calvo and Reinhart (1996) study the 1994/95 Mexican crisis using correlation coefficients and conclude there was contagion in Latin America and Asia. Using the same methodology, Baig and Goldfajn (1998) also confirm contagion in the markets of Malaysia, Indonesia, Philippines and South Korea during the 1997 Asian Crisis.

Nevertheless, it should be noted that there are some caveats when using the correlation coefficient. Forbes and Rigobon (2002) highlight that this indicator depends positively on the returns volatility. As a result, when return volatility increases during crises, the correlation coefficient may wrongly indicate the presence of contagion. These authors correct the correlation coefficient for the heteroskedasticity bias and conclude there was an absence of contagion in the Asian, the Mexican and in the 1987 USA crisis. 
Additionally, Embrechts et al. (1999) and Embrechts, Lindskog and McNeil (2003, p. 342) highlight that the correlation coefficient is only valid for normal distributions, which are rare in financial series. Moreover, Rachev et al. (2005) also indicates that the equivalence between zero correlation and independence is only valid for normal distributions; that the correlation coefficient is affected by nonlinear monotonous transformations of the variables; and that it is not defined when the variance of variables is not finite, which may occur for variables with heavy tail distributions.

Hu (2006), Rodriguez (2007), Costinot, Roncalli and Teïletche (2000), and Embrechts, Lindskog and McNeil (2003) suggest the use of copulas to avoid the limitations of using the correlation coefficient to measure financial contagion. In contrast with the correlation coefficient, which is a simple scalar measure of association between variables, Copulas characterize the relationship between variables in distributional terms. With Copulas, it is possible to extract synthetic and global measures of association between variables and local measures of dependence, which measure the dependence between variables in a particular range. It is preferable to use these indicators for measuring the dependence between variables with a non-normal distribution than the linear correlation coefficient (Embrechts et al., 2003).

When contagion is present, it is important to know how it occurs, mainly because financial crises have significant costs, and financial contagion has strong implications for international portfolio management. On this regard, the classification of contagion channels by Boyer et al. (2006) is interesting (Figure 1).

Figure 1 - Possible channels of transmission of the Subprime financial crisis

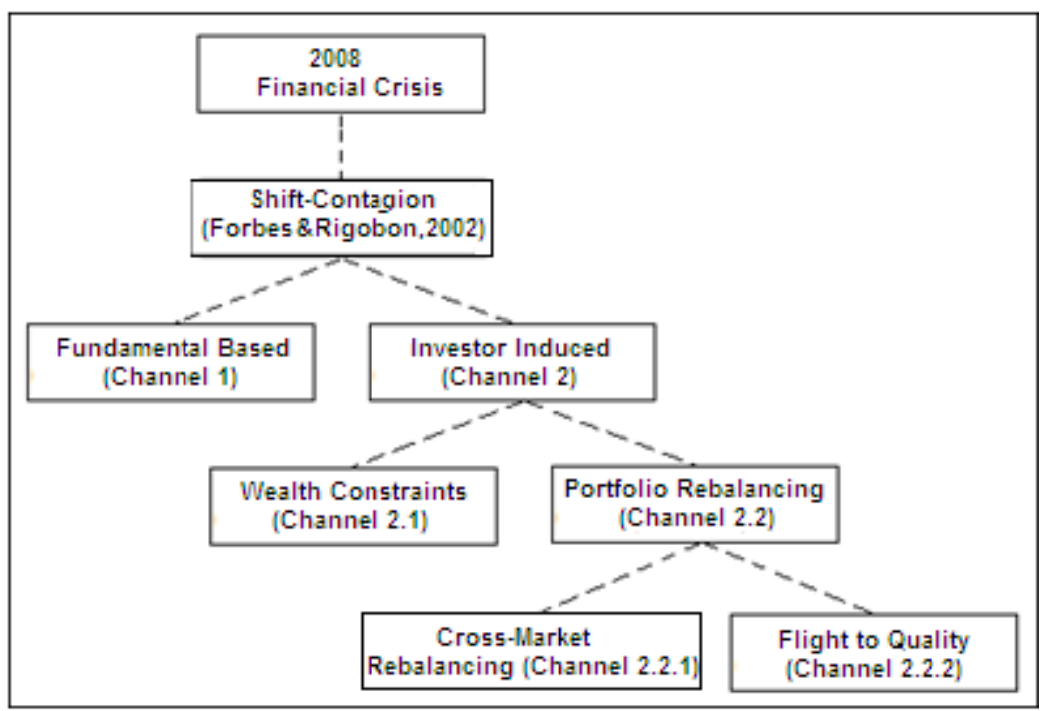

Contagion can occur through a fundamental channel or an investor related channel. When contagion is based on fundamentals, it means that it is related with real factors such as international trade and foreign direct investment. Besides this more "visible" channel, a crisis in a country changes stocks valuations in that country and in other countries. Investors change their expectations on economic 
growth, interest rates and risk assessment, and thus adjust their portfolios accordingly. Boyer et al. (2006) refers to this as portfolio rebalancing (Channel 2.2), which can take the form of cross-market rebalancing (Channel 2.2.1) or flight-to-quality (Channel 2.2.2). The former channel, also called crossmarket hedging (Cheung et al., 2009), is related to international investors who adjust portfolios to the change in countries' risk after shocks occur. In the theoretical model of Kodres and Pritsker (2002), international investors have a balanced exposure to countries' macroeconomic risks. Once there is a shock in one country, which also affect others countries' risk, investors adjust their portfolios in order to reduce the risk to which they are exposed. They not only sell assets in the targeted country of the crisis but also in other affected countries, leading to a propagation of the crisis. This mechanism may explain the propagation of crises even among countries with few trade connections, as was the case between Brazil and Russia during the 1998 Russian Crisis (Cheung et al., 2009).

In turn, the flight-to-quality channel is more connected to local investors that adjust portfolios' risk after a shock, moving funds from more risky assets to less risky assets (Boyer et al., 2006). The typical example is the sale of stocks to buy bonds in the same country. In such a case, the correlation between stock prices and bond prices decreases. Instead, if there are international investors flying from a country, then a simultaneous fall would be observed in stock and bond prices, implying an increase in correlation between prices of both assets.

Alternatively, investors may propagate crises through wealth constraints impositions (Channel 2.1). This occurs when investors suffer losses in the focus country of the crisis and have to sell assets in other countries (Kyle and Xiong, 2001). The need to sell may occur due to margin calls or to significant withdrawals from mutual funds.

In our study, we explore the fact that cross-market rebalancing and wealth constraints channels have different implications for markets" co-movement during crisis and "normal" periods. In the model of Kodres and Pritsker (2002), portfolio adjustments by international investors (Channel 2.2.1) imply that the intensity of co-movement is equal in periods of crisis and in periods of upward market movements. In contrast, the models of Kyle and Xiong (2001), Calvo (1999) and Yuan (2005), which highlight wealth constraints as the main channel of transmission, argue that correlations between markets are higher in periods of crisis than in bull markets, because liquidity constraints are present during crisis periods.

As mentioned above, the literature does not always agree on the channels causing the propagation of financial crises. As one might expect, the preponderant channel of transmission depends on the economies/markets involved, the type of event that is responsible for the crisis, the moment in time where the crisis happens, and the specific method used to measure transmission. In what follows, we focus particularly on the 2008 Subprime crisis and how it (possibly) contaminated the NYSE Euronext markets, making use of Copula theory. 


\section{DATA AND METHODOLOGY}

\subsection{THE DATA}

This study analyses how the US Subprime financial crisis was transmitted to the NYSE Euronext countries: Belgium, France, the Netherlands and Portugal. We use the Morgan Stanley Capital International (MSCI) ${ }^{2}$ stock indices and the 1-3 year Treasury bond indices from Bloomberg/EFFAS ${ }^{3}$. Both indices are observed daily and are expressed in local currency. As usual, market returns equal the logarithm differences of the daily market indices.

The data covers the period from $3^{\text {rd }}$ January 2005 to $7^{\text {th }}$ December 2009 which is assumed to be the starting date of the Sovereign Debt Crisis. Indeed, on $8^{\text {th }}$ December 2009 Fitch cut the rating of the long term Greek Debt from A- to BBB+, putting the rating of the Greek debt below level A- for the first time in ten years. The decision to end the sample in December 2009 must be understood in light of the fact that we are only interested in studying the Subprime crisis in this paper.

We chose $1^{\text {st }}$ August 2007 as the sample breakpoint in line with the existing literature ${ }^{4}$. In fact, Fry et al. (2010) claim that "the US Subprime crisis began in mid-2007..." and Gallegati (2010) acknowledges that "...the burst of the US Subprime mortgage bubble was in August 2007 (the consensus date of the crisis)...". The authors that estimated the date of the break also indicate August 2007 as the beginning of the crisis. For example, using recursive-type statistical tests to date the timeline of financial bubbles during the Subprime crisis, Phillips and $\mathrm{Yu}$ (2011) found evidence that the property price bubble emerged in August 2007. See also Longstaff (2010), Table 2, for a timeline of the events during the 2006-2008 period. Note also that in August 2007, the Bank BNP Paribas closed two mutual funds exposed to the Subprime crisis, which was seen by the markets as a significant event.

The date $1^{\text {st }}$ August 2007 is therefore used to split the sample into pre-crisis and crisis periods. Hence, our series has a total of 1230 observations $^{5}$, with 642 observations before the structural break took place and 588 observations after the burst of the Subprime bubble; this constitutes a balanced and fair amount of information for this empirical application ${ }^{6}$.

\footnotetext{
${ }^{2}$ Bloomberg tickers for the stock indices: MXUS Index, MXBE Index, MXFR Index, MXNL Index and MXPT Index.

3 Bloomberg tickers for the bond indices: USGITR Index, BEGITR Index, FRG1TR Index, NEG1TR Index and PTG1TR Index.

${ }^{4}$ At the end of February 2007 there was the first correction in the stock market related with the Subprime crisis. But in August 2007 the fall in stock markets was much more pronounced than in February 2007.

${ }^{5}$ Holidays were excluded.

${ }^{6}$ Horta et al (2010) tested alternative dates for the beginning of the crisis, and concluded that the choice of $1^{\text {st }}$ August 2007 is appropriate and does not alter the results obtained.
} 


\subsection{THE METHOD}

To explore the information that is available for the US and European markets joint distributions of risky returns and bonds, we use copula theory and the maximum likelihood approach.

The concept of copula was first introduced in finance by Embrechts et al. (1999) and refers to the joint distribution function of random variables $F\left(x_{1}, \ldots, x_{d}\right)$, which characterizes the structure of dependence between variables (the so called marginal variables). That is, a copula $C\left(u_{1}, \ldots, u_{d}\right)$ is a function in which the objects are the marginal distribution functions $F_{i}\left(x_{i}\right), i=1, \ldots, d$. Following Sklar (1959),

$$
F\left(x_{1}, \ldots, x_{d}\right)=C\left(F_{1}\left(x_{1}\right), \ldots, F_{d}\left(x_{d}\right)\right) .
$$

Firstly, it is possible to extract synthetic and global measures of association between variables, namely the Kendall's tau $(\tau)$ or the Spearman's rho $(\rho)$ statistics. Additionally, the superior (upper) and inferior (lower) tail asymptotic coefficients ( $\lambda_{U}$ and $\lambda_{L}$, respectively) can be obtained to infer about the degree of dependence of the variables of interest at the extremes of the bivariate distributions. For technical details on copula theory see Dias (2004), Nelsen (2006), Patton (2002), Schmidt (2006) and Trivedi and Zimmer (2005), among others. These tail coefficients and the Kendall's tau are both suggested in this paper to measure contagion between markets and the channels of transmission in the Subprime crisis.

The method we propose for measuring contagion and determining the main channels of financial crisis transmission can be summarized in four steps, as follows.

Step 1: Using the maximum likelihood approach, we adjust ARMA-GARCH models to the returns in order to remove autocorrelation and conditional heteroskedasticity from the series (Dias, 2004; Gonzalo and Olmo, 2005). This procedure is important to avoid significant bias in the results (Stambaugh, 1995; Boyer, Gibson and Loretan, 1999; Forbes and Rigobon, 2002). After this adjustment, the standardized residuals are recovered, now called filtered returns.

Step 2: The series of filtered returns are divided into two periods: a pre-crisis and a crisis period. Assuming that the filtered returns are iid, we adjust several parametric distributions for both periods by maximum likelihood: Gaussian, t-Student, logistic and Gumbel (this one for extreme values). Notice that the latter captures the existence of an asymmetric distribution for the returns. The distribution that best fits the series is chosen using the Akaike information criteria (AIC).

Step 3: The marginal distributions selected in Step 2 are used to adjust copulas by the Inference Functions for Margins (IFM) method $^{7}$ for each pair of returns, for the pre-crisis and the crisis periods. Then, using the AIC, the best copula is chosen from among the following copulas: Gaussian, $t$ -

\footnotetext{
${ }^{7}$ This method was proposed by McLeish and Small (1998) and consists of estimating the copula parameters in two steps, as we explain later in the paper. The first step estimates the parameters of marginal distributions. In the second step, the parameters of the copulas are obtained. One advantage of this method is that it allows for previous testing of the adjustment of the marginal distributions.
} 
Student, Frank, Gumbel, Clayton, Gumbel-Survival Gumbel and Clayton-Gumbel (Dias, 2004; Rodriguez, 2007).

In order to obtain the parameters' variance-covariance matrix and other measures associated with copulas, we propose the bootstrap technique developed by Trivedi and Zimmer (2005). This technique consists of:

a) Through the IFM method, obtain the vector of parameters $\hat{\beta}_{1}$ and $\hat{\beta}_{2}$ from the two marginal distributions and the vector of parameters $\hat{\theta}$ related to the copulas dependence measures. The joint vector of parameters is defined as $\hat{\Omega}=\left(\hat{\beta}_{1}, \hat{\beta}_{2}, \hat{\theta}\right)^{\prime}$;

b) Randomly draw with replacement a sample of observations from the original filtered returns data;

c) With the sample obtained in b), re-estimate $\beta_{1}, \beta_{2}$ and $\theta$, and store the point estimates;

d) Repeat steps b) and c) $R$ times (with $R=1000$ ) and denote the rth estimation of the parameters as $\hat{\beta}_{1}(r), \hat{\beta}_{2}(r)$ and $\hat{\theta}(r), \mathrm{r}=1, \ldots, \mathrm{R}$. The $\mathrm{rth}$ vector of parameters is $\hat{\Omega}(r)=\left(\hat{\beta}_{1}(r), \hat{\beta}_{2}(r), \hat{\theta}(r)\right)^{\prime} ;$

e) The estimators' standard-errors are defined as the square-roots of the main diagonal of the matrix $\hat{V}=R^{-1} \sum_{r=1}^{R}(\hat{\Omega}(r)-\hat{\Omega})(\hat{\Omega}(r)-\hat{\Omega})^{\prime}$.

Step 4: Using the bootstraping results for the estimated copulas, study the channels of transmission by formulating specific hypotheses of interest considering the quantities $\tau, \lambda_{U}$ and $\lambda_{L}$, which depend on $\Omega$. The corresponding bootstrap distributions of the estimated copula measures of dependence will then serve to obtain p-values for the proposed tests. Next, we describe the tests under study.

The first scenario consists of testing the existence of contagion in the Subprime financial crisis, using the definition of Forbes and Rigobon (2002). Naturally, the US stock market is understood to be the focus of the crisis. If contagion exists, then the correlation between the US stock returns and the stock returns of country i, measured by $\tau$ from the estimated copulas, increases during the crisis period when compared to the period prior to the crisis. The hypothesis of interest is therefore:

$$
\begin{aligned}
& \left\{\begin{array}{l}
H_{0}: \tau^{\text {crisis }}(i)-\tau^{\text {pre-crisis }}(i) \leq 0 \\
H_{1}: \tau^{\text {crisis }}(i)-\tau^{\text {pre-crisis }}(i)>0
\end{array}\right. \\
& i=\text { Bel, Fra, Neth, Por }
\end{aligned}
$$


where $\tau^{\text {crisis }}(i)$ measures the correlation between the US and country $i$ stock returns, for the crisis period.

If the null hypothesis is rejected, it can be concluded that contagion existed. The next step is to test which channels of contagion were active. Therefore, the second test assesses whether investors transmit the crisis due to wealth constraints (Channel 2.1) or portfolio rebalancing (Channel 2.2). In the former case, the correlation between the US stock market returns and the stock market returns of country $i$ is larger in periods of crisis than in periods of market boom. To measure the correlation between markets in periods of extreme changes in prices, we use the asymptotic tail coefficients obtained directly from the estimated copulas. Namely, for periods of significant falls in the market the lower asymptotic tail coefficient, $\lambda_{L}$, is used; and for periods of large increases in asset prices we use the upper asymptotic tail coefficient, $\lambda_{U}$. These coefficients measure the probability that a market reaches an extreme value given that the other market has already reached this value. In other words, these coefficients measure the probability that two markets suffer very high price increases or decreases simultaneously. Hence, the test compares, in the crisis period, the correlation between markets during large falls in prices with the correlation between markets during large increases in prices:

$$
\begin{aligned}
& \left\{\begin{array}{l}
H_{0}: \lambda_{L}^{\text {crisis }}(i)-\lambda_{U}^{\text {crisis }}(i) \leq 0 \\
H_{1}: \lambda_{L}^{\text {crisis }}(i)-\lambda_{U}^{\text {crisis }}(i)>0
\end{array}\right. \\
& i=\text { Bel, Fra, Neth, Por }
\end{aligned}
$$

Rejecting the null hypothesis in this second test means that the crisis is transmitted through wealth constraints.

The third test looks at the interaction between stock and bond markets during a crisis, assuming, as usual, that bonds are the less risky investment. If test 2 confirms that portfolio rebalancing is the main channel of transmission, this test allows us to distinguish if the transmission occurs due to crosscountry portfolio re-balancing or to domestic investors' flying-to-quality. On the one hand, if international investors are taking funds out of a country, they will leave from both the stock and bond markets simultaneously, implying that the correlation between both markets will increase or remain the same. On the other hand, if domestic investors are flying to quality inside the same country, they will substitute stocks with bonds. ${ }^{8}$ As a result, the correlation between stock and bond markets will decrease during the crisis.

\footnotetext{
${ }^{8}$ Notice that the channel based on international investors may also include a flight-to-quality behaviour, where investors sell domestic bonds or shares to buy safer foreign bonds or shares.
} 
Given the above, the third test compares the correlation of stock and bond markets during the crisis and before the crisis:

$$
\begin{aligned}
& \left\{\begin{array}{l}
H_{0}: \tau_{\text {Bond ,Stock }}^{\text {crisis }}(i)-\tau_{\text {Bond Stock }}^{\text {pre-crisis }}(i)<0 \\
H_{1}: \tau_{\text {Bond, Stock }}^{\text {crisis }}(i)-\tau_{\text {Bond Stock }}^{\text {pre-cris }}(i) \geq 0
\end{array}\right. \\
& i=\text { Bel, Fra, Neth, Por }
\end{aligned}
$$

with $\tau_{\text {Bond,Stock }}(i)$ as the correlation between the bond and stock market of country i. If the null hypothesis is rejected, this indicates that it is international investors that are behind the portfolio rebalancing that originates the crisis contagion. If the null hypothesis cannot be rejected, then flight-toquality is the main mechanism explaining the propagation of the crisis to the stock market.

\section{EMPIRICAL RESULTS AND DISCUSSION}

In this section, we apply the method described above to the transmission of the US Subprime financial crisis to the NYSE Euronext countries. We use daily bond and stock returns covering the period from $3^{\text {rd }}$ January 2005 to $7^{\text {th }}$ December 2009 and taking $1^{\text {st }}$ August 2007 as the starting date of the Subprime financial crisis.

As expected, the original return series have serial correlation and conditional heteroskedasticity (standard Ljung-Box-Pierce and Engle tests were performed and autocorrelation and partial autocorrelation functions were analysed). After adjusting for the best ARMA-GARCH models (See Table 1), the filtered returns were recovered confirming the absence of autocorrelation and conditional heteroskedasticity.

Table 1 - Adjusted ARMA-GARCH models to the returns under study

\begin{tabular}{llr}
\multicolumn{1}{c}{ Index } & \multicolumn{1}{c}{ Fitted Model } & $\begin{array}{c}\text { Log } \\
\text { Likelihood }\end{array}$ \\
\hline US Stocks & ARMA(1,1)-GARCH(1,1) & 3867.9 \\
FRA Stocks & ARMA(1,1)-GARCH(1,1) & 3739.7 \\
NETH Stocks & GARCH(1,1) & 3784.2 \\
BEL Stocks & GARCH(1,1) & 3756.1 \\
POR Stocks & GARCH(1,1) & 4054.0 \\
US Bonds & AR(1),AR(5),AR(10),MA(1),MA(5),MA(10)-GARCH(1,1) & 6672.1 \\
FRA Bonds & ARMA(1,1)-GARCH(1,1) & 7151.4 \\
NETH Bonds & ARMA(1,1)-GARCH(1,1) & 7150.5 \\
BEL Bonds & ARMA(1,1)-GARCH(1,1) & 7134.6 \\
POR Bonds & ARMA(1,1)-GARCH(1,1) & 7115.9
\end{tabular}

Note: the first model refers to the mean and the second to the conditional variance. 
Figure 2 provides additional information where we can observe the volatility's trend of filtered returns, obtained with the Hodrick-Prescott filter, as in Horta et al. (2010). The increase in the volatility of returns during the crisis is evident. Although the increase is initially gradual, there is a sudden increase in April 2008 when Fannie Mae and Freddie Mac were bailed out by the US Government. The peak of volatility in stock markets is reached in November 2008, two months after the peak in bond markets, coinciding with the failure of Lehman Brothers Bank.

Figure 2 - Volatility trends of filtered stock and bond returns
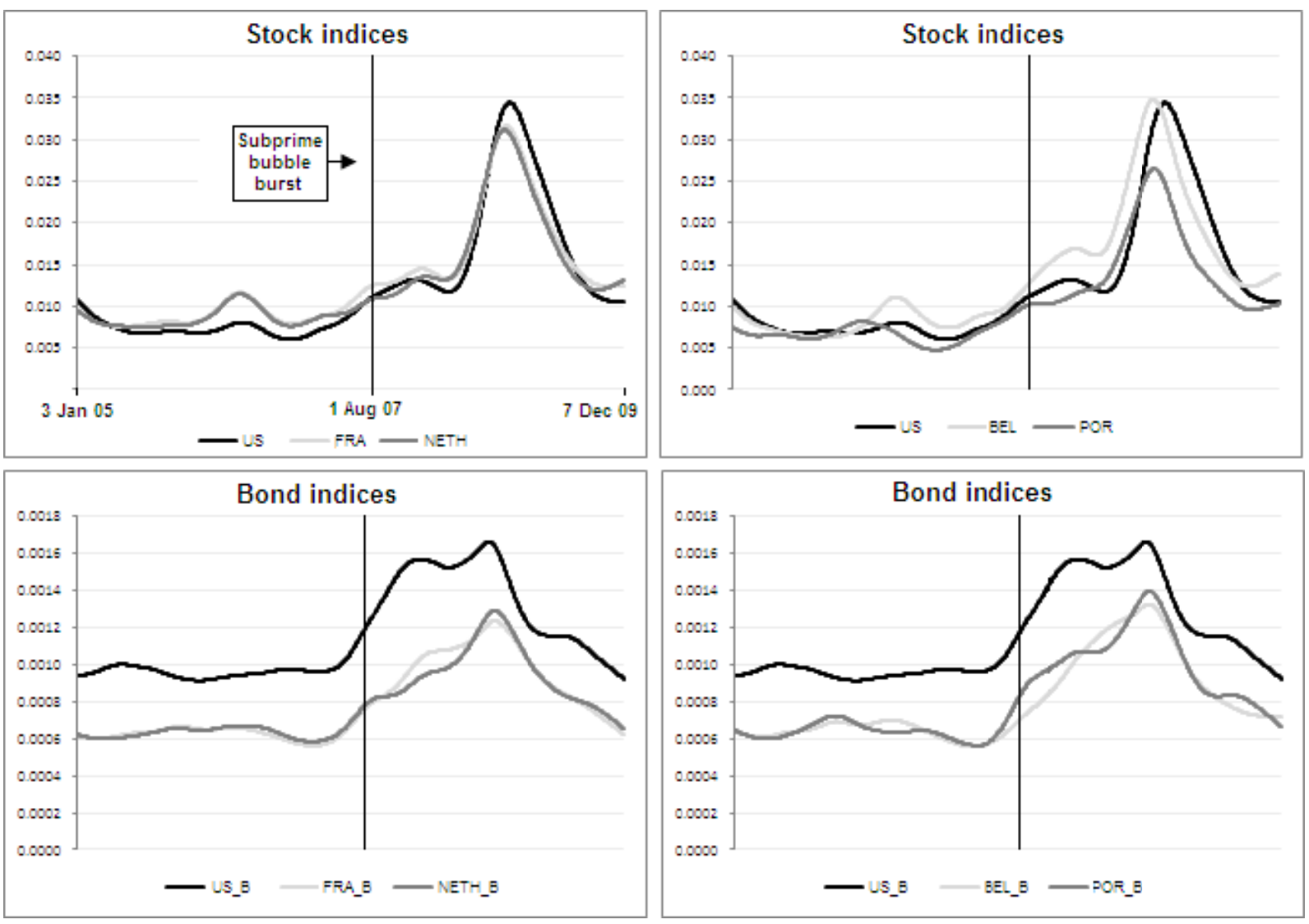

We now fit the parametric distribution functions to the filtered series. Table 2 contains the distribution functions selected for each return. With the exception of the French stock returns, which has a normal distribution during the crises period, for the remaining series it was chosen the logistic function. The prevalence of the latter function suggests the existence of heavier tails than in the Gaussian distribution (Mandelbrot and Hudson (2004) address this issue). The fact that the Gumbel distribution did not provide the best fit is in any case an indicator that there is no asymmetry in the distributions of returns. 
Table 2 - Selected distribution functions for the univariate series of filtered returns

\begin{tabular}{|c|c|c|c|c|c|}
\hline $\begin{array}{l}\text { Pre-crisis } \\
\text { period }\end{array}$ & $\begin{array}{c}\text { Selected } \\
\text { distribution }\end{array}$ & $\begin{array}{c}\text { Log } \\
\text { Likelihood }\end{array}$ & AIC & $\begin{array}{l}\mu \text { - location } \\
\text { parameter } \\
\text { (std. error) }\end{array}$ & $\begin{array}{c}\sigma \text {-scale } \\
\text { parameter } \\
\text { (std. error) } \\
\end{array}$ \\
\hline US Stocks & Logistic & 850.7 & -1697.4 & $\begin{array}{c}0.0220 \\
(0.0346)\end{array}$ & $\begin{array}{c}0.5076 \\
(0.0168)\end{array}$ \\
\hline FRA Stocks & Logistic & 865.8 & -1727.6 & $\begin{array}{c}0.0170 \\
(0.0358)\end{array}$ & $\begin{array}{c}0.5223 \\
(0.0172)\end{array}$ \\
\hline NETH Stocks & Logistic & 855.5 & $-1707,0$ & $\begin{array}{c}0.0132 \\
(0.0348)\end{array}$ & $\begin{array}{c}0.5108 \\
(0.0169)\end{array}$ \\
\hline BEL Stocks & Logistic & 855.6 & -1707.2 & $\begin{array}{c}0.0039 \\
(0.0352)\end{array}$ & $\begin{array}{c}0.5138 \\
(0.0169)\end{array}$ \\
\hline POR Stocks & Logistic & 849.7 & -1687.0 & $\begin{array}{l}-0.0065 \\
(0.0344)\end{array}$ & $\begin{array}{c}0.5049 \\
(0.0167)\end{array}$ \\
\hline US Bonds & Logistic & 731.3 & -1458.6 & $\begin{array}{l}-0.0065 \\
(0.0291)\end{array}$ & $\begin{array}{c}0.4242 \\
(0.0140)\end{array}$ \\
\hline FRA Bonds & Logistic & 740.5 & $-1477,0$ & $\begin{array}{l}-0.0210 \\
(0.0298)\end{array}$ & $\begin{array}{c}0.4327 \\
(0.0142)\end{array}$ \\
\hline NETH Bonds & Logistic & 734.3 & -1464.6 & $\begin{array}{l}-0.0224 \\
(0.0295)\end{array}$ & $\begin{array}{c}0.4287 \\
(0.0140)\end{array}$ \\
\hline BEL Bonds & Logistic & 742.3 & -1480.6 & $\begin{array}{l}-0.0343 \\
(0.0299)\end{array}$ & $\begin{array}{c}0.4338 \\
(0.0142)\end{array}$ \\
\hline POR Bonds & Logistic & 728.8 & -1453.6 & $\begin{array}{l}-0.0343 \\
(0.0291)\end{array}$ & $\begin{array}{c}0.4237 \\
(0.0139)\end{array}$ \\
\hline Crisis period & & & & & \\
\hline US Stocks & Logistic & 861.5 & -1719.0 & $\begin{array}{l}-0.0290 \\
(0.0419)\end{array}$ & $\begin{array}{c}0.5861 \\
(0.0203)\end{array}$ \\
\hline FRA Stocks & Normal & 860.2 & -1716.4 & $\begin{array}{l}-0.1021 \\
(0.0431)\end{array}$ & $\begin{array}{c}1.0459 \\
(0.0305)\end{array}$ \\
\hline NETH Stocks & Logistic & 865.0 & -1726.0 & $\begin{array}{l}-0.0741 \\
(0.0425)\end{array}$ & $\begin{array}{c}0.5926 \\
(0.0204)\end{array}$ \\
\hline BEL Stocks & Logistic & 860.1 & -1716.2 & $\begin{array}{l}-0.0780 \\
(0.0421)\end{array}$ & $\begin{array}{c}0.5871 \\
(0.0201)\end{array}$ \\
\hline POR Stocks & Logistic & 849.4 & -1694.8 & $\begin{array}{l}-0.1144 \\
(0.0411)\end{array}$ & $\begin{array}{c}0.5746 \\
(0.0198)\end{array}$ \\
\hline US Bonds & Logistic & 885.5 & -1756.8 & $\begin{array}{c}0.0547 \\
(0.0434)\end{array}$ & $\begin{array}{c}0.6076 \\
(0.0209)\end{array}$ \\
\hline FRA Bonds & Logistic & 889.1 & -1774.2 & $\begin{array}{c}0.1353 \\
(0.0428)\end{array}$ & $\begin{array}{c}0.6056 \\
(0.0211)\end{array}$ \\
\hline NETH Bonds & Logistic & 887.6 & -1771.2 & $\begin{array}{c}0.1339 \\
(0.0425)\end{array}$ & $\begin{array}{c}0.6024 \\
(0.0210)\end{array}$ \\
\hline BEL Bonds & Logistic & 888.4 & -1772.8 & $\begin{array}{c}0.1322 \\
(0.0429)\end{array}$ & $\begin{array}{c}0.6061 \\
(0.0211)\end{array}$ \\
\hline POR Bonds & Logistic & 890.9 & -1777.8 & $\begin{array}{c}0.1344 \\
(0.0429)\end{array}$ & $\begin{array}{c}0.6072 \\
(0.0212)\end{array}$ \\
\hline
\end{tabular}

NOTE: The mean of the Logistic function has the same value as the location parameter; the variance is given by $\pi 2 / 3 \sigma 2$. For the Gaussian distribution, the mean and variance are, respectively, $\mu$ e $\sigma 2$. 
Next, we adjust copulas to the bivariate series of filtered returns. Table 3 shows the results obtained for the selected copulas for the pre-crisis and crisis periods and, at each period, combining stock returns for two countries and stock and bond returns for a single country. We present copula parameters $(\theta, v$ and $w)$ and several measures obtained from the estimated copulas, namely the $\tau$ of Kendall and the asymptotic tail coefficients $\lambda_{U}$ and $\lambda_{L}$ (standard errors in parenthesis).

Regarding the period of pre-crisis returns, the t-Student copula best fits the data, with just one exception. This means that there is symmetry in the distribution of returns during pre-crisis periods. Another relevant aspect is that the extreme dependence between series, as assessed by $\lambda_{U}$ and $\lambda_{L}$, is significant. For instance, it can be observed that the US and French stock markets are the most correlated in extreme situations, presenting a probability of simultaneous movement during periods of extreme ups and downs of $14.16 \%\left(\lambda_{U}=\lambda_{L}=0.1416\right)$. Moreover, it is clear that the correlation between stock and bond markets within a country is negative, ranging between $-8.4 \%$ and $-11.8 \%$. In contrast, and as expected, stock market returns are positively correlated across countries, with correlations ranging between $32.3 \%$ for France/US and $16.0 \%$ for Portuga1/US. The correlation is stronger for larger markets, with the degree of correlation decreasing in the following order: France, the Netherlands, Belgium and Portugal.

Turning now to the crisis period, Table 3 shows that the estimated copulas for the bivariate series are in general symmetric. Only the copulas for US/FRA and US/POR stock returns present a bias to the right. In these two cases, in turbulent markets, the correlation between markets is higher when indices increase. In addition the Gaussian copula is the most chosen for the crisis period.

It can also be inferred from Table 3 that the Kendall's $\tau$ measure increases during the crisis period for all pairs of stock markets, which suggests the existence of contagion. Finally, we apply the proposed hypothesis tests to evaluate the possibility of financial contagion and to determine the main channels of transmission. 
Table 3 - Selected copulas

\begin{tabular}{|c|c|c|c|c|c|c|c|c|}
\hline & 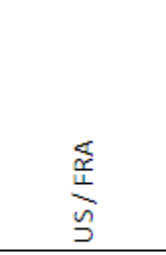 & $\frac{I}{n}$ & $\begin{array}{l}\vec{\oplus} \\
\triangleq\end{array}$ & $\begin{array}{l}\frac{r}{0} \\
\stackrel{0}{2} \\
\stackrel{2}{\supset}\end{array}$ & 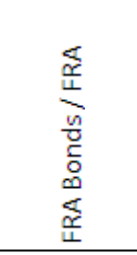 & 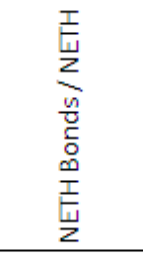 & 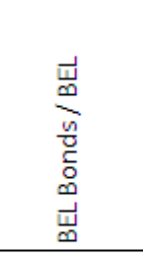 & $\begin{array}{l}0 \\
0 \\
0 \\
n \\
\frac{n}{c} \\
\vdots \\
0 \\
\infty \\
0 \\
0 \\
0\end{array}$ \\
\hline \multicolumn{9}{|l|}{ Pre-crisis period } \\
\hline Selected copula & t-Student & t-Student & t-Student & t-Student & t-Student & t-Student & t-Student & Frank \\
\hline Log Likelihood & -99.0 & -87.6 & -66.9 & -23.3 & -14.9 & -13.7 & -11.7 & -5.2 \\
\hline AIC & -194.1 & -171.2 & -129.8 & -42.7 & -25.8 & -23.4 & -19.4 & -8.4 \\
\hline Depend. Param. $(\theta 1)$ & $\begin{array}{c}0.4868 \\
(0.0250)\end{array}$ & $\begin{array}{c}0.4616 \\
(0.0258)\end{array}$ & $\begin{array}{c}0.4127 \\
(0.0252)\end{array}$ & $\begin{array}{c}0.2492 \\
(0.0277)\end{array}$ & $\begin{array}{l}-0.1856 \\
(0.0301)\end{array}$ & $\begin{array}{r}-0.1830 \\
(0.0300)\end{array}$ & $\begin{array}{c}-0.1721 \\
(0.0303)\end{array}$ & $\begin{array}{c}-0.7636 \\
(0.1698)\end{array}$ \\
\hline Deg. of freedom $(v)$ & $\begin{array}{c}6.7549 \\
(2.7052)\end{array}$ & $\begin{array}{c}7.2840 \\
(1.9548)\end{array}$ & $\begin{array}{l}10.5542 \\
(4.2567)\end{array}$ & $\begin{array}{r}12.4889 \\
(5.0788)\end{array}$ & $\begin{array}{c}7.3784 \\
(2.5324)\end{array}$ & $\begin{array}{c}8.1601 \\
(2.9047)\end{array}$ & $\begin{array}{l}10.6795 \\
(6.0421)\end{array}$ & - \\
\hline Kendall $\tau$ & $\begin{array}{c}0.3236 \\
(0.0182)\end{array}$ & $\begin{array}{c}0.3055 \\
(0.0185)\end{array}$ & $\begin{array}{c}0.2708 \\
(0.0176)\end{array}$ & $\begin{array}{c}0.1603 \\
(0.0182)\end{array}$ & $\begin{array}{c}-0.1189 \\
(0.0195)\end{array}$ & $\begin{array}{c}-0.1172 \\
(0.0194)\end{array}$ & $\begin{array}{c}-0.1101 \\
(0.0196)\end{array}$ & $\begin{array}{c}-0.0844 \\
(0.0185)\end{array}$ \\
\hline Tail $\lambda_{u}$ & $\begin{array}{c}0.1416 \\
(0.0427)\end{array}$ & $\begin{array}{c}0.1175 \\
(0.0362)\end{array}$ & $\begin{array}{c}0.0497 \\
(0.0286)\end{array}$ & $\begin{array}{c}0.0133 \\
(0.0132)\end{array}$ & $\begin{array}{c}0.0076 \\
(0.0071)\end{array}$ & $\begin{array}{c}0.0052 \\
(0.0063)\end{array}$ & $\begin{array}{c}0.0017 \\
(0.0045)\end{array}$ & - \\
\hline Tail $\lambda_{L}$ & $\begin{array}{c}0.1416 \\
(0.0427) \\
\end{array}$ & $\begin{array}{c}0.1175 \\
(0.0362) \\
\end{array}$ & $\begin{array}{c}0.0497 \\
(0.0286) \\
\end{array}$ & $\begin{array}{c}0.0133 \\
(0.0132) \\
\end{array}$ & $\begin{array}{c}0.0076 \\
(0.0071) \\
\end{array}$ & $\begin{array}{c}0.0052 \\
(0.0063) \\
\end{array}$ & $\begin{array}{c}0.0017 \\
(0.0045) \\
\end{array}$ & - \\
\hline \multicolumn{9}{|l|}{ Crisis period } \\
\hline Cópula seleccionada & $\begin{array}{c}\text { Gumbel- } \\
\text { Surv. Gumb. }\end{array}$ & t-Student & t-Student & Gumbel & Gaussian & Gaussian & Gaussian & t-Student \\
\hline Log Likelihood & -158.0 & -144.2 & -107.6 & -64.0 & -82.9 & -73.0 & -56.2 & -37.1 \\
\hline AIC & -310.0 & -284.3 & -211.2 & -126.0 & -161.9 & -142.0 & -108.4 & -70.2 \\
\hline Depend. Param. $(\theta 1)$ & $\begin{array}{c}2.0867 \\
(0.3823)\end{array}$ & $\begin{array}{c}0.6190 \\
(0.0200)\end{array}$ & $\begin{array}{c}0.5539 \\
(0.0213)\end{array}$ & $\begin{array}{c}1.4119 \\
(0.0336)\end{array}$ & $\begin{array}{l}-0.4915 \\
(0.0238)\end{array}$ & $\begin{array}{l}-0.4652 \\
(0.0235)\end{array}$ & $\begin{array}{l}-0.4148 \\
(0.0243)\end{array}$ & $\begin{array}{l}-0.3326 \\
(0.0273)\end{array}$ \\
\hline Depend. Param. $(\theta 2)$ & $\begin{array}{c}1.5560 \\
(0.2344)\end{array}$ & - & - & - & - & - & - & - \\
\hline Weight param. $(\omega 1)$ & $\begin{array}{c}0.5672 \\
(0.0832)\end{array}$ & - & - & - & - & - & - & - \\
\hline Weight param. $(\omega 2)$ & $\begin{array}{c}0.4328 \\
(0.0832)\end{array}$ & - & - & - & - & - & - & - \\
\hline Deg. of freedom $(v)$ & - & $\begin{array}{c}7.4785 \\
(2.5653)\end{array}$ & $\begin{array}{l}29.9248 \\
(8.3213)\end{array}$ & & - & - & - & $\begin{array}{l}13.2459 \\
(6.6095)\end{array}$ \\
\hline Kendall $\tau$ & $\begin{array}{c}0.4500 \\
(0.0156)\end{array}$ & $\begin{array}{c}0.4250 \\
(0.0162)\end{array}$ & $\begin{array}{c}0.3737 \\
(0.0163)\end{array}$ & $\begin{array}{c}0.2917 \\
(0.0168)\end{array}$ & $\begin{array}{l}-0.3271 \\
(0.0174)\end{array}$ & $\begin{array}{c}-0.3080 \\
(0.0169)\end{array}$ & $\begin{array}{c}-0.2723 \\
(0.0170)\end{array}$ & $\begin{array}{c}-0.2158 \\
(0.0184)\end{array}$ \\
\hline Tail $\lambda_{u}$ & $\begin{array}{c}0.3437 \\
(0.0435)\end{array}$ & $\begin{array}{c}0.1935 \\
(0.0506)\end{array}$ & $\begin{array}{c}0.0056 \\
(0.0268)\end{array}$ & $\begin{array}{c}0.3662 \\
(0.0190)\end{array}$ & - & - & - & $\begin{array}{c}0.0001 \\
(0.0009)\end{array}$ \\
\hline Tail $\lambda_{L}$ & $\begin{array}{c}0.1899 \\
(0.0420)\end{array}$ & $\begin{array}{c}0.1935 \\
(0.0506)\end{array}$ & $\begin{array}{c}0.0056 \\
(0.0268)\end{array}$ & - & - & - & - & $\begin{array}{c}0.0001 \\
(0.0009)\end{array}$ \\
\hline
\end{tabular}

NOTE: Standard errors in brakets.

To assess the existence of contagion, it is necessary to analyse the sign and significance of the change in the Kendall's tau during the crisis, denoting it by $\Delta \tau$. In order to construct the probability function for $\Delta \tau$, we considered $\mathrm{R}=1000$ replications of the bootstrap procedure. For each replication, a value 
was obtained for $\Delta \tau$. Afterwards, these 1000 values were sorted in an increasing order to obtain the p-values of the test for the null of no contagion: H0: $\Delta \tau \leq 0{ }^{9}$.

Table 4 shows the results for the first test. The conclusion is that financial contagion is present in all markets at a significance level of 1\%. In Horta et al. (2010), with a smaller sample for the crisis period, the null of no contagion had larger significance levels, reaching $8.6 \%$ for the Portuguese case. They also obtained smaller proportional increases in the Kendall's tau during the crisis period for the countries analysed, with the exception of Belgium. It can therefore be concluded that the signs of contagion generally increased as the crisis developed.

Table 4 - Results of the first test: does contagion exist?

\begin{tabular}{lrrrr}
\multicolumn{1}{c}{ Stock indices } & $\Delta \tau$ & $\Delta \tau / \tau$ & p value & Conclusion \\
\hline US/FRA & $0.1264 *$ & $39.1 \%$ & 0.000 & Contagion detected \\
US/NETH & $0.1195^{*}$ & $39.1 \%$ & 0.000 & Contagion detected \\
US/BEL & $0.1029^{*}$ & $38.0 \%$ & 0.000 & Contagion detected \\
US/POR & $0.1314 *$ & $82.0 \%$ & 0.000 & Contagion detected \\
* Significance (contagion) at 1\% leve1 & & &
\end{tabular}

Given that contagion existed during the Subprime financial crisis, we can go on to determine the main contagion channels. The second test was performed; this indicates that portfolio rebalancing was the main channel of transmission of the crisis, as opposed to wealth constraints (See Table 5). This is similar to the conclusion of Boyer et al. (2006) for the Asian crisis and in consonance with the theoretical model of contagion of Kodres and Pritsker (2002).

Table 5 - Results of the second test: wealth constraints versus portfolio rebalancing

\begin{tabular}{lccl}
\multicolumn{1}{c}{ Indices } & $\lambda_{L}-\lambda_{U}$ & p value & Conclusion \\
\hline US/FRA & -0.1538 & 0.944 & Main contagion mechanism: "portfolio rebalancing" \\
US/NETH & 0.0000 & 1.000 & Main contagion mechanism: "portfolio rebalancing" \\
US/BEL & 0.0000 & 1.000 & Main contagion mechanism: "portfolio rebalancing" \\
US/POR & -0.3662 & 1.000 & Main contagion mechanism: "portfolio rebalancing"
\end{tabular}

\footnotetext{
${ }^{9}$ The $p$-values are obtained for an unilateral test, reflecting the probability mass to the left of $\Delta \tau=0$. 
At this point, only one question remains unanswered: was the portfolio rebalancing due to crosscountry movements or to domestic investors flying to quality? To answer this question, the third test was performed and its null hypothesis was not rejected, i.e., the correlation between stocks and bonds did not increase during the crisis (Table 6). This indicates that flight-to-quality prevails over crossmarket portfolio rebalancing.

Table 6 - Results of the third test: cross market rebalancing versus flight to quality

\begin{tabular}{lccc}
\multicolumn{1}{c}{ Indices } & $\Delta \tau_{\text {Bond Stock }}$ & $\mathrm{p} \mathrm{value}$ & \multicolumn{1}{c}{ Conclusion } \\
\hline $\mathrm{FRA}^{\text {Bond }} / \mathrm{FRA}$ & -0.2082 & 1.000 & Strong evidence of flight to quality \\
$\mathrm{NETH}^{\text {Bond }} / \mathrm{NETH}$ & -0.1908 & 1.000 & Strong evidence of flight to quality \\
$\mathrm{BEL}^{\text {Bond }} / \mathrm{BEL}$ & -0.1622 & 1.000 & Strong evidence of flight to quality \\
$\mathrm{POR}^{\text {Bond } / \mathrm{POR}}$ & -0.1314 & 1.000 & Strong evidence of flight to quality
\end{tabular}




\section{CONCLUSION}

Existing studies on contagion in financial markets conclude that the investors' induced channel is the most important channel of transmission. Through this channel, contagion may occur due to investors' wealth constraints or portfolio rebalancing. Furthermore, portfolio rebalancing may be dominated by cross-market rebalancing or flight-to-quality within the same country. Despitte the several theoretical contributions, there is little empirical evidence on how the investors' induced channel works. This paper contributes to this understanding through the study of the channels of transmission of the Subprime financial crisis to four European stock markets, using the theory of copulas. The bootstrap technique is proposed to obtain the standard errors of parameters, the asymptotic tail coefficients and the Kendall's tau dependence measure, and also to perform the hypothesis tests.

Among the four European markets analysed, it is found that the biggest markets are most correlated with the US market. France has the largest correlation, followed by the Netherlands, Belgium and Portugal. Moreover, it is found that the dependence between stock and bond markets inside a given country is negative.

Evidence also shows that there was financial contagion in the four analysed markets. Furthermore, the contagion took place mainly through portfolio rebalancing as opposed to investors' wealth constraints; the adjustment in portfolios occurred at the national level, with investors reducing risk through the substitution of stocks by bonds (flight to quality).

From the above results, it can be said that the present study shows that during the Subprime financial crisis the increase of dependence between national stock markets reduced the benefits of geographic diversification. However, in the initial stages at least, portfolio diversification to bonds was a strategy that paid off in that it reduced risk and contributed to a more sound and stable financial system. 


\section{REFERENCES}

ANG, A. and Bekaert, G. (2002), "International Asset Allocation with Regime Shifts", Review of Financial Studies 15, pp.1137-1187.

ANG, A. and CHEN, P. (2002), "Asymmetric Correlations of Equity Portfolios", Journal of Financial Economics 63, pp.443-494.

BAIG, T. and Goldfajn, I. (1998), "Financial Market Contagion in the Asian Crisis", IMF Working Paper 98/155.

BOYER, B., Gibson, M. and Loretan, M. (1999), "Pitfalls in Tests for Changes in Correlations", International Finance Discussion Paper 597, Board of Governors of the Federal Reserve.

BOYER, B., Kumagai, T. and Yuan, K. (2006), "How do Crisis Spread? Evidence from Accessible and Inaccessible Stock Indices”, Journal of Finance, 61, pp.957-1003.

CALVO, G. (1999), "Contagion in Emerging Markets: When Wall Street is a Carrier", Working Paper, University of Maryland.

CALVO S. and REINHART, C. (1996), "Capital Flows to Latin America: Is There Evidence of Contagion Effects?" in G. Calvo, M. Goldstein, E. Hochreiter (eds.), Private Capital Flows to Emerging Markets After the Mexican Crisis, Institute for International Economics, Washington.

CHEUNG L., TAM, C. and SZETO, J. (2009), "Contagion of Financial Crisis: A Literature Review of Theoretical and Empirical Frameworks", Research Note 02/2009, Hong Kong Monetary Authority.

CONNOLLY, R. and WANG, A. (2003), "International Equity Market Co-movements: Economic Fundamentals or Contagion?”, Pacific-Basin Finance Journal 11, pp.23-43.

COSTINOT, A., RONCALLI, T. and TEÏLETCHE, J. (2000), "Revisiting the Dependence Between Financial Markets with Copulas", Available at SSRN: http://ssrn.com/abstract=1032535.

CHUDIK, A. and FRATZSCHER, M. (2012), "Liquidity, risk and the global transmission of the 2007-08 financial crisis and the 2010-11 sovereign debt crisis”, ECB Working Paper, No 1416, Feb. 
DIAS, A. (2004), “Copula Inference for Finance and Insurance”, Doctoral Thesis ETH No. 15283. Swiss Federal Institute of Technology, Zurich.

DUNGEY, M., Fry, R., GONZÁLEZ-HERMOSILlO, B. and MARTIN V. (2004), "Empirical Modeling of Contagion: A Review of Methodologies", IMF Working Paper WP/04/78.

DUNGEY, M., Fry, R., GONZÁLEZ-HERMOSILLO, B., MARTIN V. and TANG, C. (2008), “Are Financial Crisis Alike?", CAMA Working Papers 2008-15, Australian National University.

EMBRECHTS, P., MCNEIL, A. and STRAUMANN, D. (1999), "Correlation: Pitfalls and Alternatives", Risk, 12, pp.69-71.

EMBRECHTS, P., LINDSKOG, F. and MCNEIL, A. (2003), "Modelling Dependence with Copulas and Applications to Risk Management", in S. Rachev (ed.), Handbook of Heavy Tailed Distributions in Finance, Elsevier, pp.331-385.

FORBES, K. and RIGOBON, R. (2002), "No Contagion, only Interdependence: Measuring Stock Market Co-movements", The Journal of Finance, 57, pp.2223-2261.

FRY, R., MARTIN, V. and TANG, C. (2010), "A New Class of Tests of Contagion with Applications", Journal of Business and Economic Statistics, 28, pp.423-437.

GALlEGATI, M. (2010), “A Wavelet-Based Approach to Test for Financial Market Contagion”, Computational Statistics and Data Analysis, article in press.

GONZALO, J. and OLMO, J. (2005), "Contagion Versus Flight to Quality in Financial Markets", Economics Working Paper we051810. Universidad Carlos III.

GRUBEL, H. and Fadner, R. (1971), “The Interdependence of International Equity Markets”, Journal of Finance, 26, pp.89-94.

GUO, F., CHEN, C. and HUANG, Y. (2011), "Markets Contagion During Financial Crisis: A Regime-Switching Approach", International Review of Economics and Finance, 20, pp.95-109.

HORTA, P., MENDES, C. and VIEIRA, I. (2010), "Contagion Effects of the Subprime Crisis in the European NYSE Euronext Markets", Portuguese Economic Journal, 9, pp.115-140. 
HU, L. (2006), “Dependence Patterns Across Financial Markets: a Mixed Copula Approach”, Applied Financial Economics 16, pp.717-729.

IDIER, J. (2011), "Long Term vs. Short Term Transmission in Stock Markets: The Use of Markovswitching Multifractal Models", European Journal of Finance, 17, pp.27-48.

KAROLYI, A. and STULZ, R. (1996), "Why do Markets Move Together? An investigation of U.S.Japan Stock Return Co-movements", Journal of Finance 51, pp.951-986.

KING, M., SENTANA E. and WADHWANI S. (1994), "Volatility and Links Between National Stock Markets", Econometrica 62, pp.901-933.

KODRES, L. and PRITSKER, M. (2002), “A Rational Expectations Model of Financial Contagion”, Journal of Finance 57, pp.769-799.

KYLE, A. and XIONG, W. (2001), "Contagion as a Wealth Effect”, Journal of Finance 56, pp.14101440.

LONGIN, F. and SOLNIK, B. (2001), "Extreme Correlation of International Equity Markets", Journal of Finance 56, pp.649-676.

LONGSTAFF, F. (2010), "The Subprime Credit Crisis and Contagion in Financial Markets", Journal of Financial Economics, 97, pp.436-450.

MANDELBROT, B. and HUDSON, R. (2004), The (Mis)Behaviour of Markets: A Fractal View of Risk, Ruin and Reward, Basic Books.

MCLEISH, D. and SMALL, C. (1988), "The Theory and Applications of Statistical Inference Functions", Lecture Notes in Statistics, 44, Springer-Verlag, New York.

NELSEN, R. (2006), An Introduction to Copulas, Springer, New York.

PATTON, A. (2002), “Applications of Copula Theory in Financial Econometrics”, PhD dissertation, University of California, San Diego. 
PERICOLI, M. and SBRACIA, M. (2003), “A Primer on Financial Contagion”, Journal of Economic Surveys 17, pp.571-608.

PHILLIPS, P.C.B. and YU, J. (2011), "Dating the Timeline of Financial Bubbles During the Subprime Crisis", Quantitative Economics, 2, pp.455-491.

RACHEV, S., MENN, C. and FABOZZ, F. (2005), Fat-Tailed and Skewed Asset Return Distributions: Implications for Risk Management, Portfolio Selection, and Option Pricing, John Wiley $\&$ Sons.

RODRIGUEZ, J. (2007), “Measuring Financial Contagion: a Copula Approach”, Journal of Empirical Finance 14, 401-423.

SCHMIDT, T. (2006), “Coping with Copulas”, in J. Rank (ed.), Copulas: From Theory to Application in Finance, Risk Books, London, pp.3-34.

SHARPE, W. (1964), "Capital Asset Prices: A Theory of Market Equilibrium Under Conditions of Risk”, Journal of Finance 19, pp.425-42.

SKLAR, A. (1959), «Fonctions de Repartition à n Dimensions et Leurs Marges », Publications de l'Institute de Statistique de l'Université de Paris 8, pp.229-231.

STAMBAUGH, R. (1995), Unpublished Discussion of Katolyi and Stulz (1996), NBER Universities Research Conference on Risk Management.

TRIVEDI, P. and ZIMMER, D. (2005), "Copula Modelling: an Introduction for Practitioners", Foundations and Trends in Econometrics 1, pp.1-111.

YUAN, K. (2005), "Asymmetric Price Movements and Borrowing Constraints: A Rational Expectations Equilibrium Model of Crisis, Contagion, and Confusion”, Journal of Finance 60, pp.379-411. 